\title{
Establishing a Systems \& ICT Master program in the International Framework
}

\author{
Emmanuel WITRANT* Jean-Marc THIRIET* \\ Nicolas RETIÈRE** \\ * Control Systems Department, GIPSA-lab \\ ** G2E-lab \\ 961 rue de la Houille Blanche $B P 46$, \\ Université Joseph Fourier, Grenoble, France.
}

\begin{abstract}
This paper presents a new international master curriculum in the field of information and control technologies (ICT) focused on industrial process automation (IPA). The education objectives are set according to the latest concepts developed in ICT for process automation, with clear specifications towards engineering and industry. The curriculum, expected learning outcomes and general and specific competencies are defined following some quality specifications issued at the European level. The organization and recognition issues for student exchange objectives between the European Union (EU) and the United States of America (US) are discussed. Finally, a feedback from the first years of the program provides some insights for the students' enrollment, projects definition and possible ways of curriculum improvement. The proposed program architecture, contents and pedagogic approach can serve as a motivation for new developments in Systems \& ICT Master programs and related curriculum design.
\end{abstract}

Keywords: curriculum design, engineering education, information and control technologies in education, Master's education, systems engineering.

\section{INTRODUCTION}

Information technology (IT) components are increasingly used in complex engineering systems. As mentioned in Rantzer and Witrant (2007) and promoted by the European Embedded Control Institute (EECI 2009), the pervasive infiltration of computer systems (embedded systems and networks) in engineered products and in medicine and biology, requires transformational thinking and ideas in engineering research, education and entrepreneurship. The use of a model-based system integration methodology combined with an overall emphasis on compositional design methodology then appears as a crucial issue in modern process automation.

The international dimension is strongly encouraged by various countries in the world for the education of engineers. In Europe, the Bologna process helps at allowing exchanges of students during their studies (Bologna 1999; Martins and Thiriet 2008) and dedicated support is provided (such as ERASMUS programs). Exchanges between European and American students are allowed by international projects such as the Atlantis program, which is sponsored both by the US Department of Education and the European Commission. As a part of the generic competences expected in an international framework (Gonzalez and Wagenaar 2005; Ward 2008), multilingual competences, as well as the ability to work as a team in a multicultural environment, is required by the employees (Pilat et al. 2008). The purpose is here many fold:

- having the possibility to work within an international company, with foreign teams;

- having the possibility to manage people, in a foreign country;

- be able to discuss or negotiate, with a supplier or a customer, in an international environment.

The international M2 (second and last year of the Master program in the French education system) on Industrial Process Automation ${ }^{1}$ (M2-IPA) is part of the Master Electronique, Electrotechnique, Automatique 85 Traitement du Signal (EEATS) hosted by the department UFR PHITEM (Physique, Ingénierie, Terre, Environnement, Mécanique, former Physique-EEA). It was created in 2008 by University Joseph Fourier (UJF) to meet the previous scientific and multicultural objectives. M2-IPA focuses on industrial processes, which are becoming more and more complex, with an increasing demand in terms of safety, robustness, productivity gains and quality. This development implies an evolution of automation devices, which are no longer limited to local regulation strategies but

\footnotetext{
1 http://physique-eea.ujf-grenoble.fr/intra/Formations/ M2/EEATS/PSPI/. This program will be extended in fall 2011 to include an option on Control and System Theories and re-named as the Master 2 in Systems, Control and Information Technologies (MiSCIT).
} 
now combine sets of communicating systems. A global approach, based on real-time automation, is necessary. Automatic control engineers consequently need to get a thorough education that would allow them to act at every step of the industrial production, from process control to supervision, while taking into account communication issues and quality specifications. The proposed master program aims at providing for theoretical and technical education to tackle the automation of industrial processes in a global perspective.

The aim of this paper is to present the objectives of the M2-IPA program and its inclusion in an international and industrial environment. The specific application of the main milestones suggested by the European Commission to define a common qualification framework is described.

This work is organized as follows. The main objectives of the curriculum are first presented in Section 2, from an engineering point of view and at the international level. A detailed analysis of the expected competences is given in Section 3. The organization of the curriculum, in order to fit with both US and European requirements is described in Section 4 along with student exchange experiences. Finally, specific issues concerning the first two years observations and feedback are detailed in Section 5. programspecific issues, such as learning outcomes, projects and internship topics, are mentioned in the Appendix.

\section{MAIN OBJECTIVES}

IPA is closely related to the latest high-tech products and industrial improvements driven by the need for economic efficiency. From an education point of view, it is necessary to clearly identify the theoretical material that can sustain a successful engineering career in this field. The aim of this section is to briefly introduce the specificity associated with process automation, modern industrial plants, integration in industry and work in an international framework.

\subsection{Information technologies and process automation}

After the sudden raise and subsequent fall of the "dotcom bubble", the interest for IT is coming back on the first line of the industrial market with IP-centric and intelligent automation architectures (Partridge 2005). Most corporate systems consequently have to be updated with modern communication capabilities and system-oriented control approaches. This provides the guidelines for the curriculum design, with high level knowledge and skills for research and developments $(\mathrm{R} \& \mathrm{D})$ in process automation, from system theory to its application. Due to the interdisciplinary specificity of automatic control, it applies to all the industrial fields where modeling, optimization and real-time control are necessary.

The targeted skills aim at mastering the key aspects of process automation, for automatic control, communicating systems and supervision:

- from networks architecture and security to the management of large processes with communication capabilities;

- from control and observation theory to dynamic reconfiguration (fault tolerant);
- from modeling to supervision and diagnostic of plants and industrial processes;

- from optimization and scheduling to risk analysis.

\subsection{Modern industrial plants}

Modern industrial plants imply:

- an increased complexity and the need for communication between systems;

- crucial specifications in terms of safety, robustness, productivity and quality;

- large plants involving processes that are operated at different time-scales and for which global control approaches can bring major performance improvements;

- integrating advanced system theory with the latest high-tech automation devices.

These specific aspects of industrial plants are considered in the courses, lab exercises or supervised projects, which are oriented toward interdisciplinary solutions for industrial problems.

In order to prepare the students for the industrial world, M2-IPA focuses on developing global competencies along with the technical ones. The targeted positions are essentially in research and development, and to become a specialist in control and supervision of industrial plants. The variety of industrial sectors implies a multidisciplinary approach and specific capabilities to adapt to various environments.

\subsection{International perspectives}

The increasing need for international collaborations and business globalization in high-tech industries is answered by the fact that all the classes are given in English. The students can then acquire the appropriate vocabulary for the technical language used for process automation and practice their understanding and expression more thoroughly than in dedicated English classes. It also allows to open the master program for non French-speaking students and to create an atmosphere of international exchange.

A chance to spend a semester in a specific partner American University (scholarship and transcript recognition) is given to the best students thanks to the EU/US program "Dependable Systems International Research and Educational Experience" Atlantis (2009) (DeSIRE ${ }^{2}$, Atlantis EU project, detailed below).

\section{EXPECTED COMPETENCES}

In order to structure the pedagogical objectives, the expected learning outcomes can be distinguished from the competencies. The learning outcomes (reported in the Appendix) are associated with the specific knowledge/understanding acquired during a course and are used to specify the requirements for award of credit. On the other hand competences represent a "dynamic combination of knowledge, understanding, skills and abilities", as defined in the TUNING methodology (Gonzalez and Wagenaar 2005; Ward 2008). They result from the complete 
curriculum and from the students' ability to integrate the learning outcomes as generic professional skills.

As this master is the last year of the academic curriculum and finalizes the students' education before their professional insertion in industry, the employers expectations are of first importance. The surveys carried by Ward (2008); Ward and Thiriet (2010); Pilat et al. (2008) concerning European employers in electrical and information engineering is then referred to define the expected generic competences at the Master level. According to these surveys, five competencies were defined as the top ones expected by the employers. Their inclusion in the curriculum is attempted as follows.

Team working: the principles of dialectical interaction are first addressed in the labs, in teams of two or three. Natural affinities determine the groups' composition for the introductory labs, when the students get confidence in the topic. The students are then suggested to change the teams' composition for each lab, in order to develop their adaptability. In a small project the students are divided into two student-organized competitive teams with similar objectives. A longer project differs in the size of the teams (3-4 students) and their composition, set according to complementary backgrounds and affinity for the proposed topic.

Problem solving: this competence is first addressed with homework, graduated from guided application of the theoretical material to process design. Industrial seminars, where the importance of finding applicable solutions with tight time constraints and thanks to the available software and engineering tools, emphasize the necessity for pragmatism and control architecture design.

Concern for quality: an important transition has to be achieved at the Master level between the students habits to deliver personal works aimed at knowledge and understanding checking from their teachers, and the ability to produce technical notes or engineering tools that can be used directly at the industrial level. This aspect of the education is considered with labs and projects reports. For example, the deliverable required at the end of the long term project includes a report and a code library that ought to be used by the next generation of students (multi-years project).

Capacity for applying knowledge in practice: this capacity is developed with software-oriented and experimental laboratories. The homework also contributes with topics that imply the use of multiple theoretical concepts in practice. The projects are oriented to integrate as much theoretical knowledge as possible, thanks to the supervision by teachers with different backgrounds.

Capacity to learn: at the master level, the fundamental of individual learning is supposed to be acquired. This capacity is then more oriented toward dynamic learning, through the interactions between students and the use of available information resources to complement the traditional learning process. The project thus includes a guided bibliographical search and takes advantage of the students various backgrounds (electrical, mechanical, computer, civil or instrumental engineering) to develop multidisciplinary approaches.
At the crossing of the previous skills, we can mention the importance of developing the students' confidence in their capability to adapt in an industrial environment, away from the well-known scholar system. The ability to work in an international and intercultural environment appears as an important issue (Pilat et al. 2009), strongly supported by the European Union through mobility programs across Europe. In the conclusions of Pilat et al. (2008), the interest for entrepreneurial skills is also mentioned and such skills may be of first importance for innovation.

The previous competences and their application obviously only reflect some specific aspects of the pedagogy and each professor in the program would complement it with her/his own experience. The fact that they can only be acquired through practice render their teaching particularly difficult and one would be over-optimistic to pretend that the generic competences can be taught successfully to all the students. Nevertheless, they set some interesting guidelines for curriculum designers and may be presented to the students as complementary issues to the technical education.

\section{AN EU/US COLLABORATIVE PROGRAM}

As part of the DESIRE $E^{2}$ project, the capability to exchange students appeared as an important issue that imply a specific organization and mutual transcript recognition.

\subsection{Semester organization}

In order to allow the students' exchanges between EU and US, the curriculum is organized in two terms. The first semester, which includes most of the classes, is going from September to December. The second one is between January and June: one month of classes and five months of industrial internship. The foreign exchange students within the DeSIRE ${ }^{2}$ project are then encouraged to join the master program in fall while the master students can spend either fall or spring in the collaborative US universities. A coherent program of study is ensured by advising the students concerning their destination and the choice of classes. Advanced classes in networks, modeling and control are required but the students are encouraged to take advantage of the large number of classes proposed in the partner universities to adapt their curriculum according to their personal wishes.

\subsection{Credits transfer and recognition}

The credit transfer is achieved on a term-to-term basis and validated by the head of the program. More precisely, 30 ECTS are granted for a full load of courses in the US and the classes' transcript is provided by the host university. It is identified in the USA as a "certificate" and in the EU in a "diploma supplement" (Hilburn et al. 2008). The students receive diplomas in their respective home institutions. A reduced (four months) internship is proposed to the students that spend the spring term in the mobility program, to keep the professional orientation of the master. 


\subsection{Outgoing students}

Two french UJF students ${ }^{2}$ spent the spring 2010 semester at the University of Central Florida (UCF). Their curriculum abroad has been chosen to complement the topics taught at UJF with specialties offered at UCF. Three courses were thus selected, to provide advanced specific skills to the students while leaving enough free time for their social experience. The first semester in IPA being taught in English and with a significant amount of personal work (homework and important lab reports), the students appeared to be well prepared and got a grade point average (GPA) at UCF that was similar to their first semester results. Their final second semester transcript included both these classes and the reduced internship. It was validated by the heads of the Physics department, of the international relationships board and of the M2-IPA program.

It is interesting to note that an important degree of flexibility was allowed in the choice of the classes for credit transfer, the constraint being to match with the global program objectives rather than having to substitute specific courses of the curriculum given at UJF. This is allowed by the pedagogical validation on a semester basis and the significant history of student exchanges thanks to the ERASMUS mobility program, which probably emphasized the need for administrative flexibility in classes recognitions between universities.

\subsection{Incoming students}

While the EU to US students mobility objectives were easily met, specific problems appeared to motivate American students for a European experience. These problems, described and analyzed in Kornecki et al. (2010), can be summarized as follows.

- Course recognition: the class credits are transferred on a course-to-course basis (the specific classes syllabus have to match for the recognition by the US university).

- Financial situation: the ATLANTIS stipends cover most of the living costs for EU students but not for American students, who have higher tuition fees.

- Information provision: detailed information for each class (outline, number of meeting hours, precise syllabus, classes schedule and textbooks) has to be available both for the students decision and for credit transfer. Information about the administrative procedures, studies and university life is also needed.

- Logistics: the accordance of academic calendars to avoid the loss of a semester in the student curriculum.

The logistics issue was solved thanks to the semester organization described in Section 4.1 and a dedicated website $^{3}$ was set to complement the information provided by the UJF website. Visits of UJF professors at the partner American universities were also organized to improve the information aspects, thanks to meetings with the potential prospective students and the academic staff.

2 their experience is reported in the blog http://ujf-ucf. blogspot.com/

3 http://physique-eea.ujf-grenoble.fr/intra/Formations/M2/ EEATS/PSPI/
The course recognition issue appeared as critical, as the initial offer was not sufficient to fit with the classical curriculum required by the partner universities. The scope of the exchange program was then broadened, to include undergraduate students and propose additional topics in communications and computer sciences. The UJF offer was then completed thanks to classes taught in the international programs WiNS (bachelor on Wireless Networks and Security ${ }^{4}$ ) and MoSIG (Master of Science in Informatics at Grenoble ${ }^{5}$ ). Four American students are expected for fall 2011 at UJF, two of them staying for the spring term.

\section{FEEDBACK FROM THE FIRST THREE YEARS}

M2-IPA began in September 2008, with the curriculum described in the Appendix. During the first year, a relatively small part of the classes were taught in English. One of the goals being to offer a new specialization to the first year master (M1) students at UJF (following a French curriculum), specific care had to be taken concerning the choice of the teaching language. As the M1 students were quickly able to follow courses given in English and were eager to get extra training for their B2 diploma (English speaking certificate that is necessary for the Master diploma), a turn towards international perspectives has been taken in 2009 with $100 \%$ of the classes taught in English. This section relates some experiences and feedback from the first years concerning students' applications, class projects and industrial internships.

\subsection{Students application and recruitment}

One of the main difficulties when starting a program with international perspectives is to select the appropriate level and number of students. The recruitment process is summarized in Table 1, where the number of applicants, accepted applications, students that effectively registered and obtained diplomas are presented. A majority of applicants are from foreign countries (Algeria, People's Republic of China, Cameroon, Colombia, Guinea, Greece, Iran, Jordan, Korea, Lebanon, Morocco, Pakistan, Russia, Slovakia, Sweden, Switzerland, Tunisia and Vietnam). The next significant group is composed of students from the local M1 program, with a few applicants from M1 EEATS proposed in other French universities. The last group includes the other French diplomas (M1 in other specialties, M2 and engineers).

Comparing the acceptance rates, the local students get the highest one, as a tight selection process is performed at the M1 level and specific classes are set during this year to prepare the students for the M2 (the local students thus typically follow more classes in the direct scope of IPA during their M1 then external applicants, which improves their chances of success). The other French diplomas have a limited success, as most of those students typically already have a M2 diploma and are not accepted (the EEATS policy being to encouraged them to pursue with professional integration). As a complementary remark not reflected in Table 1 , the mean grade point average of the applicants coming from the M1 was improved

\footnotetext{
4 http://www-iut.ujf-grenoble.fr/international.html

5 http://mosig.imag.fr/ProgramEn/HomePage
} 
Table 1. Students applications and results on a comparative basis (Grenoble / non-Grenoble)

\begin{tabular}{|c|c|c|c|}
\hline & $2008 / 2009$ & $2009 / 2010$ & $2010 / 2011$ \\
\hline Applicants & 119 & 109 & 84 \\
\hline - M1 EEATS & $35(30 / 5)$ & $33(30 / 3)$ & $19(12 / 7)$ \\
\hline - other French diplomas & $15(4 / 11)$ & $17(0 / 17)$ & $22(4 / 18)$ \\
\hline - foreign diplomas & 69 & 59 & 43 \\
\hline Accepted applications & $43(36 \%)$ & $34(31 \%)$ & $35(42 \%)$ \\
\hline - M1 EEATS & $28(26 / 2)$ & $16(15 / 1)$ & $11(10 / 1)$ \\
\hline - other French diplomas & $3(2 / 1)$ & $4(0 / 4)$ & $6(0 / 6)$ \\
\hline - foreign diplomas & 12 & 14 & 18 \\
\hline Effective number of students & 12 & 14 & 15 \\
\hline - M1 EEATS & $8(7 / 1)$ & $6(6 / 0)+2$ (repeating) & $4(4 / 0)+1$ (repeating) \\
\hline - other French diplomas & $1(1 / 0)$ & $2(0 / 2)$ & $2(0 / 2)$ \\
\hline - foreign diplomas & 3 & 4 & 6 \\
\hline - ERASMUS & 0 & 0 & 2 \\
\hline Graduated students & 9 & 11 & 13 (fall semester) \\
\hline
\end{tabular}

between 2008 and 2010, the good students being typically motivated by the international perspectives.

The restricted number of students attending the program, in comparison with the number of applications, is due to the fact that the students typically express their choices for multiple M2 programs offered at UJF or other universities and take their decision once the results are known. For the foreign students, the Visa attribution also appears as an important problem.

Finally, the total number of attending students remained approximately the same between 2008 and 2010 (not counting the two repeating ones) but the academic level significantly increased. This appeared both in the applicants curriculum vitae and as a first choice for the IPA Master among good students.

\subsection{Internships}

The five month internships were carried out on various topics and in different industries or research labs, as summarized in Table A.1. The topics were mainly centered on modeling and control applications, with some contributions in supervision, algorithms and integrated process design. The network aspects, while not directly reflected in the internships titles, appear implicitly as necessary issues in the automation setups. The control implementations range from classical PID or logical setups in industrial automata to advanced model-based optimal or robust feedback strategies.

It can be noted that most students got their internships in large industries but a significant number got enrolled in SME and research labs. This motivates the importance of entrepreneurial and research skills in addition to the classical industrial ones. The collaborative internships between academic research labs and industries contribute to the transfer of knowledge between university and industry and is thus strongly encouraged. The variety of industrial markets addressed appears to be a direct consequence of the need for automation in all high-tech processes with strong efficiency needs. From the education point of view, it highlights the importance of a multidisciplinary approach to engineering problems in the process modeling and control design phases.

Most of the internships went on smoothly with effective problem solving and the host industries played a significant role in the students' education. Nevertheless, some observations can be made on the few unsatisfying experiences for future improvement of the students and internships preparation. First, the most successful internships were those with a well-defined topic and strong technical support while weaknesses appeared with too-open topics. This may reflect a lack of autonomy and the clear distinction between an internship with pedagogical objectives and the possible contribution of an experienced engineer on a similar topic. Secondly, some students get difficulties to adapt to a new topic and infer the similarities with their own knowledge. This was particularly emphasized in case of a lack of team working capabilities. Finally, the distinction between finalized work (such as an industrial report) and an academic report that aims to be corrected was not always clear, which relates to the concern for quality.

Analyzing the pedagogical drawbacks behind the previous remarks, it appears that the generic competences are of prime importance for an efficient industrial integration, the technical competences being often surpassing the actual needs. This motivated the detailed analysis of the competences and the proposed application in the curriculum presented in Section 3. The expected learning outcomes appear as the necessary engineering skills and as a way to develop the analytical and concentration capabilities.

As a future perspective, the students' autonomy with respect to the learning process may be improved thanks to e-learning tools, such as $H A D O C$ continuous control web interface (Gentil et al. 2001). More generic recent methods, such as the blended learning approach (which combines collaborative, problem-based and independent learning) described in Hoic-Bozic et al. (2009) or WELSA (adaptive learning, see Popescu et al. (2009)), may also be of major interest in the future.

\section{CONCLUSIONS}

Several issues related to the complex task of setting up a new Systems \& ICT Master program in an international environment were described. The specificities associated with modern IPA issues were discussed and motivated the proposed curriculum. Local and international frameworks analysis then induced the consideration of specific constraints on classes' organization and quality assessment. 
The expected generic competencies were set according to observations made at the European level on the industrial needs while the specific competences answered technical issues related to the automation of modern industrial processes. The feedback from the first three years illustrated the difficulties associated with student recruitment, some project examples and the students' adaptation in the industrial environment.

First years students are now employed in various areas, such as motor modeling and control in a car company, embedded system design in a SME, or network management in a bank. These jobs reflect the multidisciplinary approach of the program, which is generally well received in the industry as providing unusual and innovative skills.

This paper may provide some insights for the setup of control and IT programs, concerning the curriculum architecture in an international framework and the application of generic competences expected by the industry. It may also provide some ideas for the technical contents that may be chosen to set new programs in automatic control.

\section{ACKNOWLEDGEMENTS}

The authors would like to thank the M2-IPA students, for their motivation and belief in highest education benefits, the teaching staff, for their enthusiastic involvement in this international adventure, and the administrative staff, especially Stéphanie MOYROUD who is the secretary of this program, for their very efficient handling of the numerous administration difficulties.

We thank the European Commission, the American Department of Education and the ATLANTIS program for their support to the DeSIRE ${ }^{2}$ project (Grant Agreement for EU-US Cooperation program in Higher Education and Vocational Training, Excellence in Mobility Projects; Agreement nr 2008-1773/001-001 CPT-USMOBI). We also thank the European Commission for its support through the Network of excellence (NoE) on Highlycomplex and networked control systems (HYCON2, ICT Call 5, FP7-ICT-2009-5).

Finally, we are grateful to University Joseph Fourier, and more specifically to UFR PHITEM for the support and housing of this program.

\section{REFERENCES}

Atlantis (2009). Dependable systems international research and educational experience DeSIRE ${ }^{2}$. http: // www.desire.agh.edu.pl.

Bologna (1999). The Bologna Declaration on the European space for higher education: an explanation. http://ec.europa.eu/education/policies/ educ/bologna/bologna.pdf.

EECI (2009). European embedded control institute. http: //www.eeci-institute.eu.

Gentil, S., Ploix, S., Béteau, J.F., Exel, M., and Khenouf, H. (2001). Hadoc, an internet based environment for control learning. In IFAC Symposium Internet Based Control Education. Madrid, Spain. http:// www-hadoc . lag. ensieg.inpg.fr.

Gonzalez, J. and Wagenaar, R. (eds.) (2005). Tuning Educational Structure in Europe. Final Report Pilot
Project - Phase $1 \&$ Phase 2. Tuning project, Deusto and Groningen.

Hilburn, T., Thiriet, J.M., Kornecki, A., Grega, W., and Sveda, M. (2008). Innovations 2008 World Innovations in Engineering Education and Research, chapter 4: Credits and Accreditation in the U.S.A. and Europe: Towards a Framework for transnational engineering degrees, 29-42. Begell House Publishing.

Hoic-Bozic, N., Mornar, V., and Boticki, I. (2009). A blended learning approach to course design and implementation. IEEE Transactions on Education, 52(1), 19-30.

Kornecki, A., Grega, W., and Gonzalez, A. (2010). Europe/usa mobility exchange in engineering: Why is it less attractive to the american students? In Proc. of the EAEEIE Annual Conference. Palanga, Lithuania.

Martins, M. and Thiriet, J.M. (eds.) (2008). Overview of the Bologna Process - Implementation in Europe in Electrical and Information Engineering. EAEEIE, Nancy-Grenoble.

Partridge, C. (2005). Technology moved on as executives stood still. The Times.

Pilat, A., Kornecki, A., Thiriet, J.M., Grega, W., and Rysavy, . (2009). Inter-university project based on lego nxt. In $18^{\text {th }}$ IEEE International Conference on Control Applications, part of 2009 IEEE Multiconference on Systems and Control, 1248-1253. Saint Petersburg, Russia.

Pilat, A., Kornecki, A., Thiriet, J.M., Grega, W., and Sveda, M. (2008). Industry feedback on skills and knowledge in real-time software engineering. In $19^{t h}$ annual EAEEIE Conference, 129-133. Tallinn, Estonia.

Popescu, E., Bădică, C., and Moraret, L. (2009). Intelligent Distributed Computing III, volume 237/2009, chapter WELSA: An Intelligent and Adaptive WebBased Educational System, 175-185. Springer Berlin / Heidelberg.

Rantzer, A. and Witrant, E. (2007). Opportunities and challenges in distributed embedded control. In ARTEMIS Annual Conference. Berlin, Germany.

UJF-IPA (2009). International master on industrial processes automation. http://physique-eea. ujf-grenoble.fr/intra/Formations/M2/EEATS/ PSPI/.

Ward, A. (ed.) (2008). Application of the TUNING methodology to Electrical and Information Engineering, to identify competences. Nancy-Grenoble, EAEEIE edition.

Ward, A. and Thiriet, J.M. (2010). How well aligned are the views of generic competence development between electrical and information engineering students, their faulty and their employers? In $9^{\text {th }}$ International Conference on Information Technology Based Higher Education and Training. 


\section{Appendix A. PROGRAM-SPECIFIC ISSUES}

\section{A.1 Learning outcomes}

The expected theoretical knowledge is earned by the students during the classes and labs. Major technical topics associated with IPA define the teaching units (TU). Each unit potentially includes several (one to three) classes and the related labs, in order to reflect the fact that different point of views can be considered in a topic, each one being defended by a key specialist in the field. The TU and their main objectives are defined as follows.

Modeling and real-time applications: this class introduces multi-physics modeling of complex dynamical systems, with different classes of models, identification and estimation methods. It defines the concepts, methodologies and tools for the development of real-time and embedded systems applications, emphasizing the need for analysis and control-oriented models. Graphical and analytical softwares $\left(\right.$ Labview $^{\circledR}$, Matlab $^{\circledR}$ and Scilab $\left.^{\circledR}\right)$ for control applications are presented. Specific issues related to numerical and analogical data acquisition, filtering and computer-control for real-time applications are detailed and illustrated on a field-programmable gate array (FPGA) circuit.

Multi-objective control: focused on model-based control approaches, the mathematical properties of the system provide a global system understanding that allows to evaluate the control limitations and to ensure quality specification constraints. Process optimization and regulation robustness can thus be achieved while taking into account the nonlinearities in the control design. The presented theoretical principles are illustrated with robotic applications and study cases involving complex control applications (intelligent buildings, tokamak, ventilation processes).

Networks and industrial computation: the need for communication between subsystems is a key issue in modern large-scale plants. This topic starts with the fundamental of networks topology, architecture design and communication. The students then become familiar with the different medium and norms available (Ethernet, CAN, ASI, WiFi, Zig-Bee...) and, at the user level, implement safety and security specifications. The labs present the application to wireless sensing, industrial automata and field buses.

Advanced discrete event systems: the management of interlaced tasks associated with industrial processes and the design of timed-automaton is considered in this topic. The students learn to handle tasks scheduling, technical data, logistics and large-scale simulations. Markov chains and Petri nets are also presented. The illustrative examples introduce the fundamental of conception and design for industrial plants.

Safety, supervision and diagnosis: most of the previous notions are integrated in this class. It gives the students basic notions situating control loops or data acquisition systems in the hierarchical context of monitoring and supervision. The concepts for preliminary safety analysis are defined and the basic tools for online monitoring and diagnosis of dynamic systems are described.
Communication and project management: some emphasis is set on the need for communication capabilities, especially to present results that have a high technical level in a synthetic and understandable way. The effective use of available multimedia supports (slides, website and technical report) is then specifically addressed. The management class provides for the bases of project management as well as good practices in industries. The quality management according to ISO standards and the piloting by process are presented through industrial projects. This class contains a method to establish a CV as well as simulations of real recruitment interviews.

\section{A.2 Specific competences}

The consistency of the curriculum implies some interactions between the expected learning outcomes in order to tackle specific technical problems. Such interactions, requiring an interdisciplinary approach to the learning outcomes, define the specific competences expected from the students:

- definition of performance specifications and quality constraints;

- model-based control of large-scale systems;

- networked control systems;

- remote control and embedded systems;

- multi-scale process regulation;

- optimized automation design and guaranteed quality specifications;

- service-oriented network design;

- tasks optimization for communicating devices.

Each item results from the combination of two or more TU and can be used as a basis to define illustrative benchmarks, products and projects.

\section{A.3 Long term project}

This five months project (in parallel with the theoretical classes) investigates new automation solutions for realtime feedback operation and the minimization of industrial processes energy consumption. This automation is based on distributed sensing capabilities, networked sensors, physical modeling for the process automation design and real-time feedback control. Different projects were proposed:

- zone mapping and path optimization with communicating robots;

- heat pump automation for energy savings;

- under floor air distribution (UFAD) for intelligent buildings;

- water distribution design for green building automation;

- robot design and stabilization with embedded control algorithms.

All the projects were structured similarly, as the students were asked to:

(1) analyze the project objectives and description of work to determine the research schedule, including specific milestones with the key technical issues and the titles and overview of deliverables; 
(2) perform an exhaustive bibliographical research to be able to clearly state the actual available technology and propose some innovative improvements;

(3) propose different models of the plants, stressing out the key points and necessary assumptions, along with the design of a real-time simulator;

(4) define the control problem, in terms of objectives, costs and constraints, and compare different control approaches;

(5) provide a detailed technical solution for building an experimental facility that illustrates the main realtime closed-loop control issues.

The previous objectives are highly demanding, in order to reveal the main difficulties that one may face when managing a real project. Appropriate project management and task scheduling appeared as a crucial issue. Most of the students had difficulties to quickly find and synthesize the large amount of information provided by the web or university library. There was also a strong tendency to remain stuck in technical details and team working sometimes appeared as a major difficulty, both for the team leader and collaborative workers. The social skills then appeared as important as the technical skills for an efficient work progress. At the end, the students greatly appreciated having their own project and to overcome technical challenges by themselves.

The specific organization of the project, with multiple professors supervising multiple projects, appeared particularly interesting in comparison with the more classical architecture where one professor supervises a single team. Indeed, it was beneficial for the students' autonomy as the teachers appeared as consultants according to their own research specialty rather then project supervisors. The numerous scheduled meetings contributed to build a structured approach to the project development and to handle the teams difficulties "online".

As an example, the UFAD project has now been carried over three years with several topics that illustrate the different curriculum objectives:

- intelligent buildings and the use of under-floor cool air injection, in which the students analyzed the available industrial solutions and potential interest of this application (thus setting the general project goals);

- controlled air momentum in stratified flows, focused on the study of the impact of floor diffusers and generated temperature gradients within a room;

- 0-D modeling and automation of an experimental benchmark, to determine the size and specificity of the experiment depicted in Figure A.1;

- local vs. MIMO control of the rooms temperature, to compare the use of local PID loops in each room with a robust MIMO controller, on the simulator;

- data acquisition and embedded control with the Zigbee motes, mainly focused on real-time programming and protocols.

The experimental benchmark was built by the UJF technical team and IPA students hired in industrial projects, thanks to regional and UJF funding. Additional "long term" projects will be set on the experimental aspects in

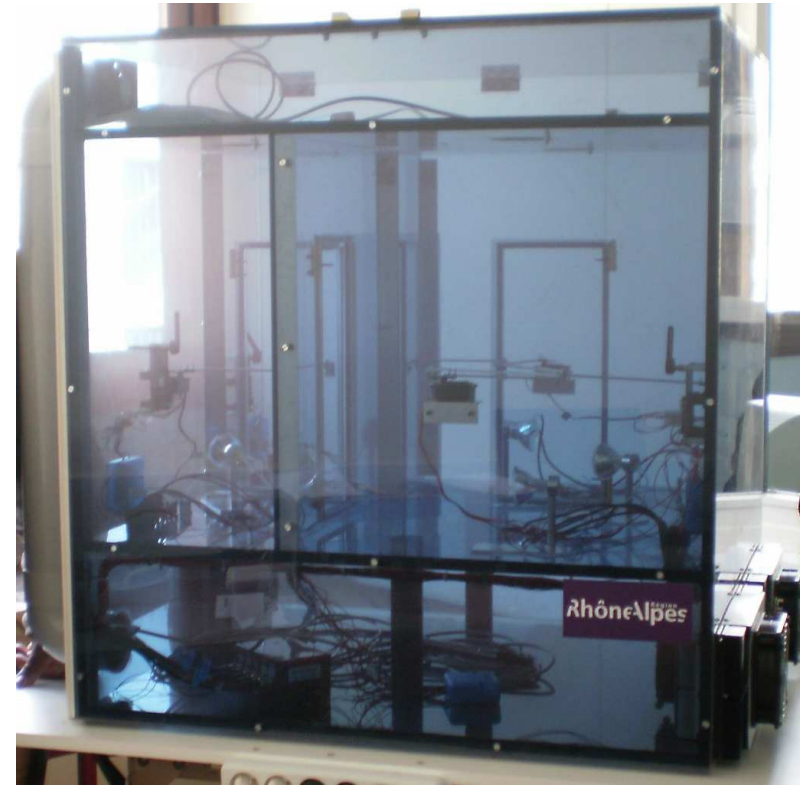

(a) Overview of the experimental benchmark

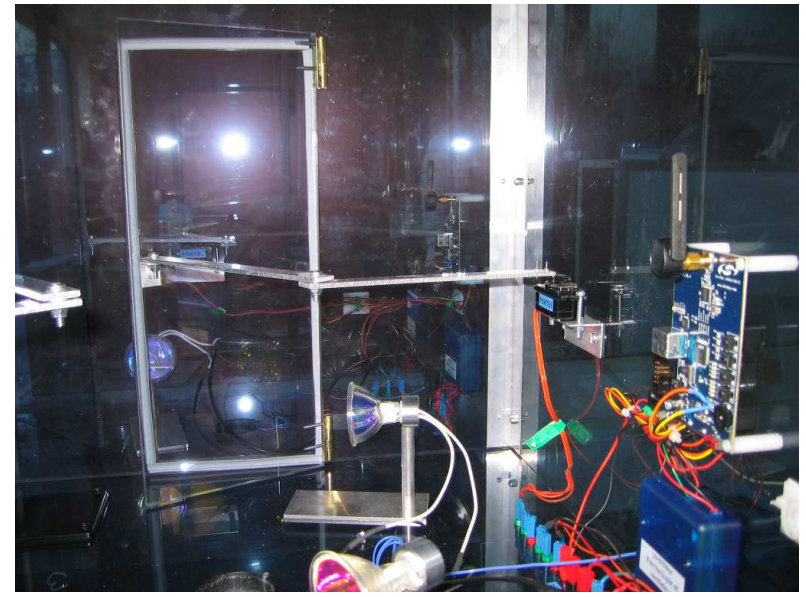

(b) Zigbee communication modules

Fig. A.1. Example of a long term project: the UFAD experiment. The air is cooled in the lower plenum by Peltier modules and then injected in each room thanks to fans, regulated from temperature measurements by Zigbee modules. Disturbances are generated by the light bulbs (heating effect) and opening/closing of doors. The heated air naturally flows into the upper plenum, where it is driven back in the underfloor.

the future and the final goal is to make the benchmark available for classical labs for other students. 
Table A.1. Internships in 2008-2011 (*: in - or in collaboration with - academic research labs)

\begin{tabular}{|c|c|c|}
\hline Internship topic & Ind. size & Indust. market \\
\hline 2008-2009 & & \\
\hline Air path modeling and control in gas motors* & Large & Automotive \\
\hline Bats localization and trajectory tracking & SME & Electronics \\
\hline Conception of control laws and electronic cards for damping systems & SME & Equipment \\
\hline Control of a running machine & Large & Electric \\
\hline Design of an automated functional test bench for electronic cards 1016-B & SME & Automation \\
\hline Development of algorithms for full electro hydraulic excavators & Large & Equipment \\
\hline Improvement of WinCC data exploitation and supervision development under zenOn & Large & $\begin{array}{l}\text { Agribusiness / bio- } \\
\text { pharmaceutics }\end{array}$ \\
\hline Optimization of linear and nonlinear PID filters for the control of DC/DC buck converters & Large & Microelectronic \\
\hline Source determination in non-homogeneous dissipative media: application to tokamaks* & Large & Energy \\
\hline $\begin{array}{l}\text { Validation software for ciphering algorithms } \\
\text { 2009-2010 }\end{array}$ & Large & Electricity \\
\hline Aerology optimization experiments for intelligent building ventilation* & SME & Research \\
\hline Air path control in diesel engines & Large & Automotive \\
\hline Automation of a Burn-In lab & Large & Microelectronic \\
\hline Automation of a measurement chain & SME & Automation \\
\hline Detection of rail internal defects by merging decisions made with ultrasonic sensor & Large & Transport \\
\hline Dynamic and multi-criteria reconfiguration in power distribution networks & SME & Research \\
\hline Embedded control with wireless sensing capabilities for UFAD automation* & SME & Research \\
\hline Identification of a Markov chain to model heat exchange in buildings* & SME & Research \\
\hline Identification of a simple thermal building model & Large & Construction \\
\hline Kinematics optimization for an insect-like robot* & SME & Research \\
\hline $\begin{array}{l}\text { Traffic model calibration methods for simulation of the Grenoble south ring* } \\
\mathbf{2 0 1 0 - 2 0 1 1}\end{array}$ & Large & Research \\
\hline Data aquisition and control for a fuel cell process & Large & Energy \\
\hline Development of neurofeedback method of EEG activity using online beam-forming & Large & Medicine \\
\hline Dynamic study of an electrical endurance testbench & Large & Electrical \\
\hline Leader-Follower robots controlled to find a communication network* & SME & Research \\
\hline Modeling and automation of a CO2 LHC-tracker cooling plant* & Large & Physics \\
\hline Modeling and control of semi-active car dampers & SME & Automotive \\
\hline Motors individual control for a multiaxes system & Large & Physics \\
\hline Predicting powder hymidity in fluid bed & Large & Chemistry \\
\hline Sensor network for traffic control & SME & Transport \\
\hline Smart energy systems and wireless sensor networks* & Large & Research \\
\hline Study and development of a PC software for firmware downloading & Large & Electrical \\
\hline
\end{tabular}

